\title{
A Common Fixed Point Theorem for occasionally weakly compatible maps in Dislocated Metric Space
}

\author{
P. Srikanth Rao and Veena Kulkarni \\ Mathematics Department B.V. Raju Institute of Tecnology, Narsapur, Medak, Telangana State., 502313,INDIA
}

Abstract: In this paper we establish a common fixed point theorem for six self of occasionally weakly compatible maps in dislocated metric space which generalizes and improves similar fixed point results.

Mathematics Subject Classification: 47H10, 54H25

Keywords: dislocated metric, weakly compatible maps, common fixed point, occasionally weakly compatible maps

\section{Introduction}

In 1922, S. Banach proved a fixed point theorem for contraction mapping in metric space. Since then a number of fixed point theorems have been proved by different authors and many generalizations of this theorem have been established. In 2000, P. Hitzler and A. K. Seda [10] introduced the notion of dislocated metric space in which self distance of a point need not be equal to zero.They also generalized the famous Banach contraction principle in this space.The study of common fixed points of mappings in dislocated metric space

satisfying certain contractive conditions has been at the center of vigorous re-search activity. Dislocated metric space plays very important role in topology, logical programming and in electronics engineering. C. T. Aage and J. N. Salunke [2], A. Isufati [1] established some important fixed point theorems in single and pair of mappings in dislocated metric space. The purpose of this paper is to establish a common fixed point theorem for two pairs of occasionally weakly compatible mappings in dislocated metric space. Our result generalizes and improves the similar results of fixed points.

\section{Preliminaries}

Now we start with the following definitions, lemmas and theorems.

Definition 2.1 [4]: Let $\mathrm{X}$ be a non empty set and let $\mathrm{d}: \mathrm{X} \times \mathrm{X} \rightarrow[0, \infty)$ be a function satisfying the following conditions:

(i) $d(x, y)=d(y, x)$

(ii) $d(x, y)=d(y, x)=0$ implies $x=y$.

(iii) $d(x, y) \leq d(x, z)+d(z, y)$ for all $x, y, z \in X$.

Then $\mathrm{d}$ is called dislocated metric (or simply d-metric) on X.

Definition 2.2 [10]: A sequence $\left\{x_{n}\right\}$ in a d-metric space (X,d) is called a Cauchy sequence if for given $\epsilon>0$, there corresponds $\mathrm{n}_{0} \in \mathrm{N}$ such that for all $\mathrm{m}, \mathrm{n} \geq \mathrm{n}_{0}$, we have $\mathrm{d}\left(\mathrm{x}_{\mathrm{m}}, \mathrm{x}_{\mathrm{n}}\right)<\epsilon$.

Definition 2.3 [10]: A sequence in d-metric space converges with respect to $d$ (or in $d$ ) if there exists $x \in$ Xsuch that $d\left(x_{n}, x\right) \rightarrow 0$ as $n \rightarrow \infty$.

In this case, $\mathrm{x}$ is called limit of $\left\{\mathrm{x}_{\mathrm{n}}\right\}$ (in $\mathrm{d}$ )and we write $\mathrm{x}_{\mathrm{n}} \rightarrow \mathrm{x}$.

Definition 2.4 [10]: A d-metric space $(\mathrm{X}, \mathrm{d})$ is called complete if every Cauchy sequence in it is convergent with respect to $\mathrm{d}$.

Definition 2.5 [10]: Let $(X, d)$ be a d-metric space. A map $M: X \rightarrow X$ is called contraction if there exists a number $\lambda$ with $0 \leq \lambda<1$ such that $\mathrm{d}(\mathrm{Mx}, \mathrm{My}) \leq \lambda \mathrm{d}(\mathrm{x}, \mathrm{y})$.

Lemma 2.6 [6]: Let $(X, d)$ be a d-metric space. If $M: X \rightarrow X$ is a contraction function, then $\left\{M^{n}\left(x_{0}\right)\right\}$ is a Cauchy sequence for each $\mathrm{x}_{0} \in \mathrm{X}$.

Lemma 2.7 [10]: Limits in a d-metric space are unique.

Definition 2.8 [5]: Let A and B be mappings from a metric space (X,d) into itself. Then, A and B are said to be weakly compatible if they commute at their coincident point; that is, $\mathrm{Ax}=\mathrm{Bx}$ for some $\mathrm{x} \in \mathrm{X}$ implies $\mathrm{ABx}=\mathrm{BAx}$.

Theorem 2.9 [9]: Two self maps $f$ and $g$ of a set $X$ are occasionally weakly compatible(OWC) iff there is a point $\mathrm{x} \in \mathrm{X}$ which is a coincidence point of $\mathrm{f}$ and $\mathrm{g}$ at which $\mathrm{f}$ and $\mathrm{g}$ commute.

Theorem 2.10 [10]: Let (X,d) be a complete $\mathrm{d}$-metric space and let $\mathrm{M}: \mathrm{X} \rightarrow \mathrm{X}$ be a contraction mapping, then $\mathrm{M}$ has a unique fixed point. 


\section{Main Results:}

Theorem3.1: Let $(X, d)$ be a complete d-metric space. Let A,B,S,T,L,M: $X \rightarrow X$ be mappings satisfying,

(3.1.1) $\mathrm{M}(\mathrm{X}) \subset \mathrm{AB}(\mathrm{X}), \mathrm{L}(\mathrm{X}) \subset \mathrm{ST}(\mathrm{X})$

(3.1.2) The pairs (L,AB) and $(\mathrm{M}, \mathrm{ST})$ are occasionally weakly compatible and

(3.1.3) $d($ Lx, My $) \leq \alpha d(A B x, M y)+\beta d(S T y, L x)+\gamma d(A B x, S T y)$

For all $\mathrm{x}, \mathrm{y} \in \mathrm{X}$ where $\alpha, \beta, \gamma \geq 0,0 \leq \alpha+\beta+\gamma<\frac{1}{2}$.

Then $\mathrm{AB}, \mathrm{ST}, \mathrm{L}$ and $\mathrm{M}$ have a unique common fixed point.

If the pairs $(\mathrm{A}, \mathrm{B}),(\mathrm{T}, \mathrm{S}),(\mathrm{M}, \mathrm{S}),(\mathrm{L}, \mathrm{A}),(\mathrm{M}, \mathrm{T})$ and $(\mathrm{L}, \mathrm{B})$ are commuting then $\mathrm{A}, \mathrm{S}, \mathrm{M}, \mathrm{T}, \mathrm{L}$ and $\mathrm{B}$ have a unique common fixed point in $\mathrm{X}$

Proof:

Using condition (3.1.1), we define sequences $\left\{\mathrm{x}_{\mathrm{n}}\right\}$ and $\left\{\mathrm{y}_{\mathrm{n}}\right\}$ in $\mathrm{X}$ by the rule,

$\mathrm{y}_{\mathrm{n}}=\mathrm{STx}_{2 \mathrm{n}+1}=\mathrm{Lx}_{2 \mathrm{n}}$, and

$$
\mathrm{y}_{2 \mathrm{n}+1}=\mathrm{ABx}_{2 \mathrm{n}+2}=\mathrm{Mx}_{2 \mathrm{n}+1}, \mathrm{n}=0,1,2 \ldots .
$$

If $\mathrm{y}_{2 n}=\mathrm{y}_{2 \mathrm{n}+1}$ for some $\mathrm{n}$, then $\operatorname{STx}_{2 n+1}=\mathrm{Mx}_{2 \mathrm{n}+1}$. Therefore $\mathrm{x}_{2 \mathrm{n}+1}$ is a coincidence point of ST and M. Also, if $y_{2 n+1}=y_{2 n+2}$ for some $n$, then $A_{B x} x_{2 n+2}=L x_{2 n+2}$. Hence $x_{2 n+2}$ is a coincidence point of $L$ and $A B$.

Assume that $\mathrm{y}_{2 \mathrm{n}} \neq \mathrm{y}_{2 \mathrm{n}+1}$ for all $\mathrm{n}$. Then, we have $\mathrm{d}\left(\mathrm{y}_{2 \mathrm{n}}, \mathrm{y}_{2 \mathrm{n}+1}\right)=\mathrm{d}\left(\operatorname{Lx}_{2 \mathrm{n}}, \mathrm{Mx}_{2 \mathrm{n}+1}\right)$

$$
\begin{aligned}
& \leq \alpha \mathrm{d}\left(\mathrm{ABx}_{2 \mathrm{n}}, \mathrm{Mx}_{2 \mathrm{n}+1}\right)+\beta \mathrm{d}\left(\mathrm{STx}_{2 \mathrm{n}+1}, \mathrm{Lx}_{2 \mathrm{n}}\right)+\gamma \mathrm{d}\left(\mathrm{ABx}_{2 \mathrm{n}}, \mathrm{STx}_{2 \mathrm{n}+1}\right) \\
& \leq \alpha \mathrm{d}\left(\mathrm{y}_{2 n-1}, \mathrm{y}_{2 \mathrm{n}+1}\right)+\beta \mathrm{d}\left(\mathrm{y}_{2 \mathrm{n}}, \mathrm{y}_{2 \mathrm{n}}\right)+\gamma \mathrm{d}\left(\mathrm{y}_{2 \mathrm{n}-1}, \mathrm{y}_{2 \mathrm{n}}\right) \\
& \leq \alpha\left[\mathrm{d}\left(\mathrm{y}_{2 \mathrm{n}-1}, \mathrm{y}_{2 \mathrm{n}}\right)+\mathrm{d}\left(\mathrm{y}_{2 \mathrm{n}}, \mathrm{y}_{2 \mathrm{n}+1}\right)\right]+\beta\left[\mathrm{d}\left(\mathrm{y}_{2 \mathrm{n}-1}, \mathrm{y}_{2 \mathrm{n}}\right)+\mathrm{d}\left(\mathrm{y}_{2 \mathrm{n}}, \mathrm{y}_{2 \mathrm{n}+1}\right)\right] \\
& +\gamma \mathrm{d}\left(\mathrm{y}_{2 \mathrm{n}-1}, \mathrm{y}_{2 \mathrm{n}}\right) \\
& =(\alpha+\beta+\gamma) d\left(y_{2 n-1}, y_{2 n}\right)+(\alpha+\beta) d\left(y_{2 n}, y_{2 n+1}\right)
\end{aligned}
$$

So, $\mathrm{d}\left(\mathrm{y}_{2 \mathrm{n}}, \mathrm{y}_{2 \mathrm{n}+1}\right) \leq \frac{\alpha+\beta+\gamma}{1-\alpha-\beta} \mathrm{d}\left(\mathrm{y}_{2 \mathrm{n}-1}, \mathrm{y}_{2 \mathrm{n}}\right)$

This shows that,

$$
=h d\left(y_{2 n-1}, y_{2 n}\right) \quad \text { where, } \mathrm{h}=\frac{\alpha+\beta+\gamma}{1-\alpha-\beta}<1
$$

$$
d\left(y_{n}, y_{n+1}\right) \leq h d\left(y_{n-1}, y_{n}\right) \leq \cdots \leq h^{n} d\left(y_{0}, y_{1}\right)
$$

For every integer $\mathrm{q}>0$, we have

$$
\begin{aligned}
d\left(y_{n}, y_{n+q}\right) \leq & d\left(y_{n}, y_{n+1}\right)+d\left(y_{n+1}, y_{n+2}\right)+d\left(y_{n+2}, y_{n+3}\right)+\cdots+d\left(y_{n+q-1}, y_{n+q}\right) \\
& \leq\left(1+h+h^{2}+\ldots+h^{q-1}\right) d\left(y_{n}, y_{n+1}\right) \\
& \leq \frac{h^{n}}{1-h} d\left(y_{0}, y_{1}\right) \quad \text { Since, } 0<h<1, h^{n} \rightarrow 0 \text { as } n \rightarrow \infty .
\end{aligned}
$$

So, we get $d\left(y_{n}, y_{n+q}\right) \rightarrow 0$. This implies $\left\{y_{n}\right\}$ is a Cauchy sequence in a complete dislocated metric space. So, there exists a point $z \in X$ such that $\left\{y_{n}\right\} \rightarrow z$.

Therefore, the subsequence's,

$\left\{\mathrm{Lx}_{2 \mathrm{n}}\right\} \rightarrow \mathrm{z},\left\{\mathrm{STx}_{2 \mathrm{n}+1}\right\} \rightarrow \mathrm{z},\left\{\mathrm{Mx}_{2 \mathrm{n}+1}\right\} \rightarrow \mathrm{z}$ and $\left\{\mathrm{ABx}_{2 \mathrm{n}+2}\right\} \rightarrow \mathrm{z}$.

Since the pair $(\mathrm{L}, \mathrm{AB})$ are occasionally weakly compatible so by definition there exists a point $u \in X$ such that $\mathrm{Lu}=\mathrm{ABu}$ and $\mathrm{LABu}=\mathrm{ABLu}$

Again, the pair $(\mathrm{M}, \mathrm{ST})$ are occasionally weakly compatible, so by definition there exists a point $v \in X$ such that $\mathrm{Mv}=\mathrm{STv}$ and $\mathrm{MST}=\mathrm{STMv}$

First, we show that $\mathrm{Lu}=\mathrm{Mv}$

From (3.1.3)

$\mathrm{d}(\mathrm{Lu}, \mathrm{Mv})$

$$
\begin{aligned}
& \leq \alpha \mathrm{d}(\mathrm{ABu}, \mathrm{Mv})+\beta \mathrm{d}(\mathrm{STv}, \mathrm{Lu})+\gamma \mathrm{d}(\mathrm{ABu}, \mathrm{STv}) \\
& \leq \alpha \mathrm{d}(\mathrm{Lu}, \mathrm{Mv})+\beta \mathrm{d}(\mathrm{Lu}, \mathrm{Mu})+\gamma \mathrm{d}(\mathrm{Lu}, \mathrm{Mv})
\end{aligned}
$$

which is a contradiction. This implies that $\mathrm{Lu}=\mathrm{Mv} \leq(\alpha+\beta+\gamma) \mathrm{d}(\mathrm{Lu}, \mathrm{Mv})$

therefore $\mathrm{Lu}=\mathrm{ABu}=\mathrm{ST}=\mathrm{Mv}$

Moreover, if there is another point $\mathrm{z}$ such that $\mathrm{ABz}=\mathrm{Lz}$ then from (3.13) it follows that $\mathrm{ABz}=\mathrm{Lz}=\mathrm{Mv}=\mathrm{STv}$ or $\mathrm{Lz}=\mathrm{Lu}$ and $\mathrm{w}=\mathrm{Lu}=\mathrm{ABu}$ is the unique point of coincidence of $\mathrm{L}$ and $\mathrm{AB}$.

thus $L L u=L A B u=A B L u$ which says that $L u$ is also a point of coincidence of $L$ and $A B$. Since the point $w=L u$ is unique, $\mathrm{ABLu}=\mathrm{LLu}=\mathrm{Lu}$ and $\mathrm{w}=\mathrm{Lu}$ is a common fixed point of $\mathrm{L}$ and $\mathrm{AB}$. Moreover, if $\mathrm{w}$ is any common fixed point of $\mathrm{L}$ and $\mathrm{AB}$, then $\mathrm{w}^{\prime}=\mathrm{Lw} \mathrm{w}^{\prime}=\mathrm{ABw} \mathrm{w}^{\prime}=\mathrm{w}$ by the uniqueness of the point of coincidence. Similarly there is a unique point $\mathrm{z} \in \mathrm{X}$ such that $\mathrm{Mz}=\mathrm{STz}=\mathrm{z}$. Suppose that $\mathrm{w} \neq \mathrm{z}$ using (3.1.3)

$$
\begin{aligned}
\mathrm{d}(\mathrm{w}, \mathrm{z}) & =\mathrm{d}(\mathrm{Lw}, \mathrm{Mz}) \\
& \leq \alpha \mathrm{d}(\mathrm{ABw}, \mathrm{Mz})+\beta \mathrm{d}(\mathrm{STz}, \mathrm{Lw})+\gamma \mathrm{d}(\mathrm{ABw}, \mathrm{STz}) \\
& =\alpha \mathrm{d}(\mathrm{w}, \mathrm{z})+\beta \mathrm{d}(\mathrm{z}, \mathrm{w})+\gamma \mathrm{d}(\mathrm{w}, \mathrm{z}) \\
& =(\alpha+\beta+\gamma) \mathrm{d}(\mathrm{w}, \mathrm{z})
\end{aligned}
$$

a contradiction. This shows that $d(w, z)=0$. Since $(X, d)$ is a dislocated metric space, so we have $w=z$. Hence $\mathrm{z}$ is the unique common fixed point of $\mathrm{AB}, \mathrm{ST}, \mathrm{L}$ and $\mathrm{M}$ 
Finally we need to show that. $\mathrm{z}$ is a common fixed point of $\mathrm{A}, \mathrm{B}, \mathrm{L}, \mathrm{M}, \mathrm{S}$ and $\mathrm{T}$.

Since $(A, B),(A, L),(B, L)$ are commutative

$\mathrm{Az}=\mathrm{A}(\mathrm{ABz})=\mathrm{A}(\mathrm{BAz})=(\mathrm{AB}) \mathrm{Az}$;

$\mathrm{Az}=\mathrm{ALz}=\mathrm{LAz}$

$\mathrm{Bz}=\mathrm{B}(\mathrm{ABz})=(\mathrm{BA})(\mathrm{Bz})=(\mathrm{AB})(\mathrm{Bz}) ; \mathrm{Bz}=\mathrm{BLz}=\mathrm{LBz}$

Which shows that $A z, B z$ are common fixed points of $(A B, L)$ yielding then by $A z=z=B z=L z=A B z$ in the view of uniqueness of common fixed point of the pairs $(A B, L)$.

Similarly using the, commutativity of $(\mathrm{S}, \mathrm{T}),(\mathrm{S}, \mathrm{M})$ and $(\mathrm{T}, \mathrm{M})$ it can be shown that $\mathrm{Sz}=\mathrm{z}=\mathrm{Tz}=\mathrm{Mz}=\mathrm{STz}$.

Therefore $\mathrm{Sz}=\mathrm{z}=\mathrm{Tz}=\mathrm{Mz}=\mathrm{Az}=\mathrm{Bz}=\mathrm{Lz}$.

Which shows $z$ is a common fixed point of A,B,L,M,S and T.

We can easily prove the uniqueness of $z$ from (3.1.3)

This establishes the theorem.

Taking $\mathrm{T}=\mathrm{B}=\mathrm{I}_{\mathrm{x}}$ identity self map in the theorem 3.1

3.2 Corollary:Let $(\mathrm{X}, \mathrm{d})$ be a complete $\mathrm{d}$-metric space. Let $\mathrm{A}, \mathrm{S}, \mathrm{L}, \mathrm{M}: X \rightarrow X$ be mappings satisfying,

(3.2.1) $\mathrm{L}(\mathrm{X}) \subseteq \mathrm{S}(\mathrm{X}), \mathrm{M}(\mathrm{X}) \subseteq \mathrm{A}(\mathrm{X})$

(3.2.2) $d(L x, M y) \leq \alpha d(A x, M y)+\beta d(S y, L x)+\gamma d(A x, S y)$

For all $\mathrm{x}, \mathrm{y} \in \mathrm{X}$ where $\alpha, \beta, \gamma \geq 0,0 \leq \alpha+\beta+\gamma<\frac{1}{2}$.

Suppose further that $(\mathrm{M}, \mathrm{S})$ and $(\mathrm{L}, \mathrm{A})$ are occasionally weakly compatible then

$\mathrm{S}, \mathrm{A}, \mathrm{L}$ and $\mathrm{M}$ have a unique common fixed point in $\mathrm{X}$

Taking $\mathrm{L}=\mathrm{M}$ and $\mathrm{T}=\mathrm{B}=\mathrm{I}_{\mathrm{x}}$ in theorem 3.1 we get the following corollary.

3.3 Corollary: Let $(X, d)$ be a complete d-metric space. Let $A, S, L: X \rightarrow X$ be mappings satisfying,

(3.3.1) $\mathrm{L}(\mathrm{X}) \subseteq \mathrm{A}(\mathrm{X}), \mathrm{L}(\mathrm{X}) \subseteq \mathrm{S}(\mathrm{X})$

(3.3.2) the pairs $(\mathrm{L}, \mathrm{S})$ and $(\mathrm{L}, \mathrm{A})$ are occasionally weakly compatible

(3.3.3) $\mathrm{d}(\mathrm{Lx}, \mathrm{Ly}) \leq \alpha \mathrm{d}(\mathrm{Ax}, \mathrm{Ly})+\beta \mathrm{d}(\mathrm{Sy}, \mathrm{Lx})+\gamma \mathrm{d}(\mathrm{Ax}, \mathrm{Sy})$

For all $\mathrm{x}, \mathrm{y} \in \mathrm{X}$ where $\alpha, \beta, \gamma \geq 0,0 \leq \alpha+\beta+\gamma<\frac{1}{2}$.

then $\mathrm{S}, \mathrm{A}$ and $\mathrm{L}$ have a unique common fixed point in $\mathrm{X}$

Taking $\mathrm{A}=\mathrm{S}$ and $\mathrm{T}=\mathrm{B}=\mathrm{I}_{\mathrm{x}}$ in theorem 3.1 we get the following corollary.

3.4 Corollary: Let $(X, d)$ be a complete d-metric space. Let $A, L, M: X \rightarrow X$ be mappings satisfying,

(3.4.1) $\mathrm{L}(\mathrm{X}) \subseteq \mathrm{A}(\mathrm{X}), \mathrm{M}(\mathrm{X}) \subseteq \mathrm{A}(\mathrm{X})$

(3.4.2) the pair (L, A) and (M, A) are occasionally weakly compatible mappings and

(3.4.3) $d(L x, M y) \leq \alpha d(A x, M y)+\beta d(A y, L x)+\gamma d(A x, A y)$

For all $\mathrm{x}, \mathrm{y} \in \mathrm{X}$ where $\alpha, \beta, \gamma \geq 0,0 \leq \alpha+\beta+\gamma<\frac{1}{2}$.

and $\mathrm{A}(\mathrm{X})$ is a complete subspace of $\mathrm{X}$ then $\mathrm{L}, \mathrm{M}$ and $\mathrm{A}$ have a unique common fixed point in $\mathrm{X}$

Taking $\mathrm{L}=\mathrm{M}$ and $\mathrm{A}=\mathrm{S}$ and $\mathrm{T}=\mathrm{B}=\mathrm{I}_{\mathrm{x}}$ in theorem 3.1 we get the following corollary.

3.5 Corollary: Let $(X, d)$ be a complete $d$-metric space. Let $A, L: X \rightarrow X$ be mappings satisfying

(3.5.1) $\mathrm{L}(\mathrm{X}) \subseteq \mathrm{A}(\mathrm{X})$,

(3.5.2) the pairs $(\mathrm{L}, \mathrm{A})$ is occasionally weakly compatible mappings

(3.5.3) $d(L x, L y) \leq \alpha d(A x, L y)+\beta d(A y, L x)+\gamma d(A x, A y)$

For all $\mathrm{x}, \mathrm{y} \in \mathrm{X}$ where $\alpha, \beta, \gamma \geq 0,0 \leq \alpha+\beta+\gamma<\frac{1}{2}$.

then $\mathrm{L}$ and $\mathrm{A}$ have a unique common fixed point in $\mathrm{X}$

Remarks: Our result generalizes the result of A. Isufati [1] and improves the results of C. T. Aage and J. N. Salunke [[2], [3]], R. Shrivastava, Z. K. Ansari and M. Sharma [11], K. P. R. Rao and P. Rangaswamy [8], K. Jha, K. P. R. Rao and D. Panthi [7], K. Jha and D. Panthi[6]and similar other results of fixed point in the literature.

\section{References}

[1]. A. Isufati, Fixed Point Theorem in Dislocated Quasi-Metric Space, Ap-plied Math. Sci., 4 (5),(2010), $217-223$.

[2]. C. T. Aage and J. N.Salunke, The Results on Fixed Points theorems in Dislocated and Dislocated Quasi-Metric Space, Applied Math. Sci., 2 (59)(2008), $2941-2948$.

[3]. C. T. Aage and J. N. Salunke, Some Results of Fixed Point Theo-rem in Dislocated Quasi-Metric Spaces, Bull. Marathwada Math. Soc., 9 (2),(2008), 1-5

[4]. F. M. Zeyada, G. H. Hassan and M. A. Ahmed, A Generalization of a fixed point theorem due to Hitzler and Seda in dislocated quasi-metric spaces, The Arabian J. Sci. Engg., 31 (1A)(2006), 111-114.

[5]. G. Jungck and B.E. Rhoades, Fixed Points For Set Valued Functions without Continuity, Indian J. Pure Appl. Math., 29 (3)(1998), 227-238.

[6]. K. Jha and D. Panthi, A common fixed point theorem in Dislocated metric space, Appl. Mathematical Sci. Vol. 6 (2012), (44974503)

[7]. K. Jha, K. P. R. Rao and D. Panthi, A Common Fixed Point Theorem For Four Mappings in Dislocated Quasi- Metric Space, Int. J. Math. Sci. Engg. Appls., 6 (1) (2012), 417-424.

[8]. K. P. R. Rao and P. Rangaswamy, Common Fixed Point Theorem for Four Mappings in Dislocated Quasi-metric Space, The Nepali 
Math. Sci. Report, 30 (1-2), 2010, 70-75.

[9]. M. A. Al- Thagafi and N. Shahazad, A note on occasionally weakly compatible maps, Int. J. Math. Anal. 3(2) (2009), 55-58

[10]. [10] P. Hitzler and A. K. Seda, Dislocated Topologies, J. Electr. Engg., 51 (12/s),(2000), 3-7..

[11]. R. Shrivastava, Z. K. Ansari and M. Sharma, Some Results on Fixed

[12]. Points in Dislocated and Dislocated Quasi-Metric Spaces, J. Advance Studies in Topology, 3 (1)(2012), 25-31

[13]. S. K. Vats, Weakly Compatible Maps in Metric Spaces, J. Indian Math. Soc., 69 (1-4), (2002), 139-143. 